\title{
Effect of Detergents and Other Amphiphiles on the Stability of Pharmaceutical Drugs
}

\author{
ANSELMO GOMES DE OLIVEIRA AND HERNAN CHAIMOVICH* \\ Departamento de Farmacos e Medicamentos, Faculdade de Ciências Farmacêuticas, Universidade Estadual Paulista, Araraquara, \\ and *Departamento de Bioquimica, Instituto de Quimica, Universidade de São Paulo, Caixa Postal 20780, São Paulo, SP. \\ CEP 01498-970, Brazil
}

The diversity of applications of amphiphiles such as surfactants and phospholipid-like compounds in pharmaceutical technology renders the study of their interactions with pharmacologically active drugs of particular relevance (Gibaldi \& Feldman 1970; Knight 1981; Voigth \& Bornschein 1982; Attwood \& Florence 1983). Amphiphiles aggregate in excess water to yield a variety of supramolecular structures (Fendler 1982; Israelachvili 1985). Basic knowledge of drug-aggregate interactions in micelles, microemulsions and liposomes must be taken into account in the development of novel, more specific and more stable pharmaceutical products (El-Nokaly \& Friberg 1982; Attwood \& Florence 1983; Jayakrishnan et al 1983; Martini et al 1984; Gasco et al 1988 a, b; Keipert et al 1989).

Reviews on micellar structure and micellar effects on chemical reactivity are available (Fendler 1982; Bunton \& Savelli 1986). Here, we will focus on the effects of aqueous micelles on drug stability. The review is organized to emphasize the chemical reaction modified by micelles rather than drug type or family of therapeutic compounds.

There have been a number of qualitative descriptions of micellar effects on drug stability. However, the applicability of these studies is severely limited, since at times it is difficult to interpret qualitative results with existing models or to generalize to conditions other than those reported. The main purpose of this review is to emphasize the relevance of quantitative studies of micellar effects on drug stability, especially where the study has allowed a thorough dissection of the aggregate effects in the rate or mechanism of the reaction. The existence of models for the quantitative analysis of micellar effects on reaction rates allows the design of adequate experimental conditions, analysis of experimental data and, most importantly, the prediction of the effects of micelles under a variety of conditions.

\section{Micelles}

Detergents, constituted by a polar head-group and a hydrocarbon chain equivalent to more than eight methylene groups, associate spontaneously in water to form dynamic aggregates denominated micelles (Tanford 1980; Fendler 1982; Israelachvili 1985). These aggregates, and many others

Correspondence: H. Chaimovich, Departamento de Bioquimica, Instituto de Quimica, Universidade de São Paulo, Caixa Postal 20780, São Paulo, SP, CEP 01498-970, Brazil. formed by amphiphiles, confer unique properties on the solution. Micelles exhibit an interfacial region separating the polar bulk aqueous phase from the hydrocarbon-like interior (Tanford 1980; Israelachvili 1985). In oil-in-water microemulsions, the micelle interior may contain added oil. The interfacial region (also called the Stern layer) has a width equivalent to the detergent head-group and, in the case of ionic detergents, contains the ionic head-groups, a fraction of the counter-ions and water (Tanford 1980; Fendler 1982; Israelachvili 1985; Bunton \& Savelli 1986). The Stern layer is extremely anisotropic causing properties of this region to change abruptly over a distance of a few angstroms. The anisotropy of the aggregate renders micellar solutions a special medium in which hydrophobic, amphiphilic or ionic compounds may be solubilized and reagents may be concentrated or separated in aqueous solution (Fendler 1982; Bunton \& Savelli 1986). A cartoon representing a micelle of a negatively charged detergent (Israelachvili 1985) is presented in Fig. 1.

In micellar solutions, as in other microheterogeneous systems, rate modifications may result from at least two unrelated factors: reagent compartmentalization and differences in the free energy of activation and the mechanism of the reaction in the aggregate. Separation of these components requires quantitative analysis of the effects of the aggregate on the reaction. Several models allow the calculation of rate constants in the micelle (Martinek et al 1977; Romsted 1977; Quina \& Chaimovich 1979; Fendler 1982; Bunton \& Savelli 1986). Monomers, substrates and micelles redistribute in solution much faster than the rate of thermal reactions (Fendler 1982; Bunton \& Savelli 1986). Monomers and substrates exchange in the $\mu$ s time-scale and ion-ion exchange rates are rapid relative to the lifetime of the micelle (Almgren et al 1977). Thus, most of the models for the quantitative analysis of micellar reactions either assume a micellar pseudophase or consider that the micellar ensemble can be treated with a cell model, where all cells contain micelles with identical composition.

The association of neutral substrates to micelles can be described by association or partitioning constants $\left(\mathrm{K}_{\mathrm{s}}\right)$. A review on the forms of analysing micelle-neutral substrate partitioning has been published (Sepulveda et al 1986). The binding of ions or ionic substrates to ionic micelles cannot be described by a simple partitioning (Quina \& Chaimovich 1979). Pseudophase models with explicit consideration of ion 


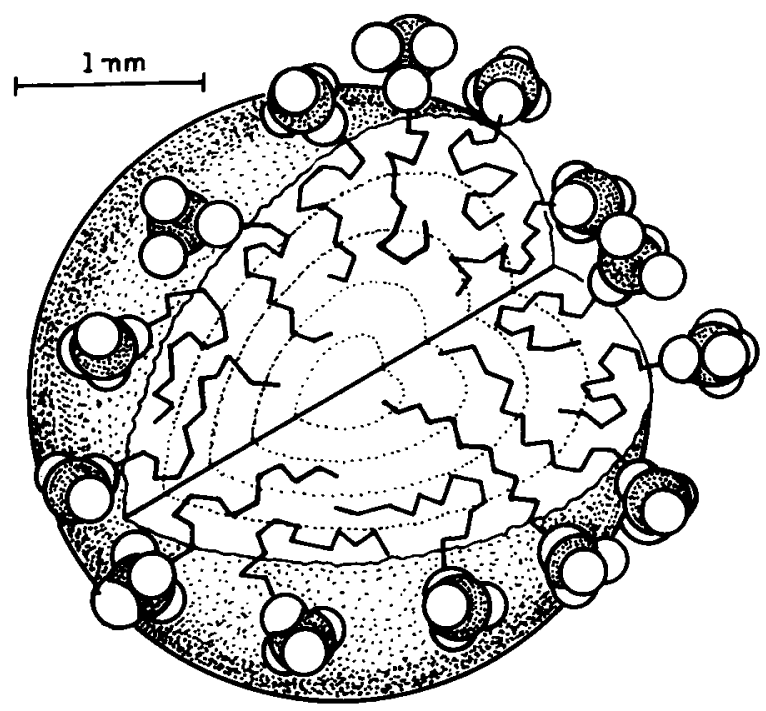

Fig. 1. A micelle of a negatively charged detergent (Israelachvili 1985).

exchange (PPIE model) treat the binding of an ionic substrate $\mathrm{X}$ in an ionic micelle with similarly charged counter-ions ( $\mathrm{Y}$ ) using a selectivity coefficient for ion exchange $\left(K_{X / Y}\right)$.

A more general form of analysing the association of ions to ionic micelles, with no assumptions concerning the constancy of micellar surface charge, is based on the use of cell models and Poisson-Boltzmann ion distributions, with Volmer or Langmuir isotherms to take into account the ion specificity, or non-electrostatic component for ion binding (PBE model, Bunton \& Savelli (1986)). Quantitative analyses and the accompanying theories for ion binding to zwitterionic micelles have recently been described (Baptista et al 1992). Therefore, it is possible to analyse quantitatively the binding of uncharged or charged substrates to neutral, zwitterionic and ionic micelles using adequate models under a wide variety of conditions.

Neutral and ionic species associate with micelles, particularly ionic micelles, through different mechanisms. Neutral substrates associate hydrophobically and the distribution constants may increase with added salt (Sepulveda et al 1986; Oliveira et al 1990, 1991). The increase in the activity coefficient of the substrate with salt may increase the difference in the standard chemical potential for watermicelle transfer $\left(\Delta \mu_{\mathrm{wm}}^{\mathrm{o}}\right)$ (where the chemical potential does not contain any electrostatic component) $\left(\Delta \mu_{\mathrm{wm}}^{\mathrm{o}}=\mu_{\mathrm{w}}^{\mathrm{o}}-\mu_{\mathrm{m}}^{\mathrm{o}}\right)$ for water-micelle transfer (Lissi et al 1985, 1986). For ionic substrates, the effects of salt will depend on a balance between the effect of ionic strength on $\Delta \mu_{\text {wm }}^{\mathrm{o}}$ and the specific effect of salt on the electrical potential at the micellar surface. Using ion-exchange terminology the salt effects on substrate binding to ionic micelles may also be described as follows: if the non-electrostatic component of the ion exchange constant is large, added salts may increase the binding of hydrophobic ions (Quina \& Chaimovich 1979). In the case of a hydrophilic ion, added salts will always displace the ion from the Stern layer and, consequently, inhibit the binding to the micelle. Difficulties and differences in interpretations in describing micellar effects also arise from the form and units that describe the association or binding of a neutral substrate to micelles (Sepulveda et al 1986).

Quantitative analysis of reactions in micellar solutions demands further assumptions concerning the separation of micellar and intermicellar reaction rates. For thermal reactions, which are slower than the monomer-micelle equilibration rates, most models assume two rate constants, namely one in the micelle $\left(\mathrm{k}_{\mathrm{m}}\right)$ and one in the intermicellar aqueous phase $\left(k_{w}\right)$. Estimates of absolute values of rate constants for bimolecular (or higher order) reactions in micelles are further complicated by assumptions concerning volume elements, necessary for the calculation of local concentrations. In spite of the assumptions, quantitative analysis of micellar reactions has been successful in providing insights into the effects of these aggregates on the kinetics and chemistry of reactions occurring in supramolecular aggregates.

The PPIE model is of great conceptual and operational simplicity and has been used with success to analyse quantitatively a wide variety of reactions in micelles and other amphiphile aggregates such as microemulsions and vesicles (Fendler 1982; Kawamuro et al 1991). The PPIE model, however, is only applicable when the concentration of added ions is relatively small with respect to the total concentration of added ionic surfactant. The PPIE model also fails with high concentrations of highly hydrated ions, such as $\mathrm{OH}^{-}$or $\mathrm{F}^{-}$(Bunton \& Savelli 1986). PBE models have provided the needed complement to PPIE to analyse quantitatively reactions under conditions which can be extended to the analysis of the effects of micelles and other aggregates on the stabilization or destabilization of pharmaceutically important drugs.

\section{Esters}

The mechanism of ester hydrolysis has been elucidated in detail (Bruice \& Benkovic 1966; Jencks 1987). A description of the mechanism of water attack on esters is shown in Scheme 1 .

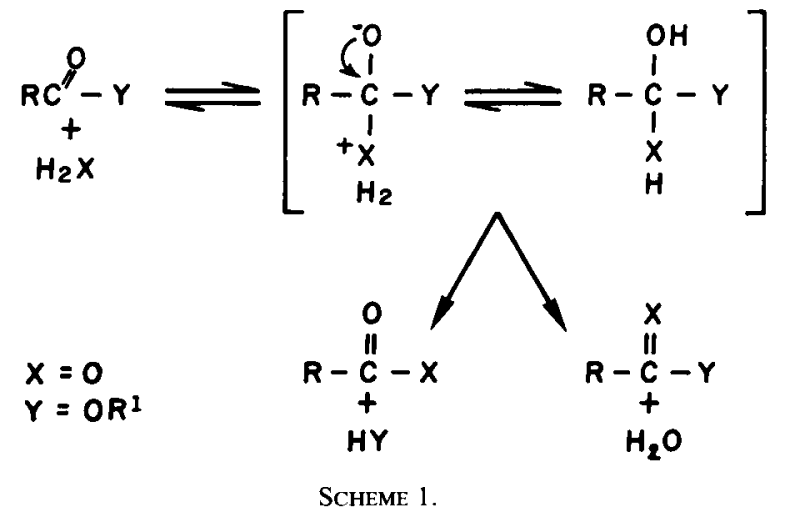

The stability of the tetrahedral intermediate (Scheme 1) depends on several factors, including the presence of acidbase catalysts and the ester structure. The effect of micelles on ester hydrolysis has been extensively investigated (Fendler 1982; Bunton \& Savelli 1986; Correia et al 1991). The rate-limiting step for alkaline hydrolysis of esters in ionic micelles is, as in water, $\mathrm{OH}^{-}$attack. Micelles, however, increase the sensitivity of the reaction to polar effects (Correia et al 1991). As a rule, in $\mathrm{OH}^{-}$-mediated ester 
hydrolysis, postively-charged micelles increase and negatively-charged micelles reduce the reaction rate. Uncharged micelles decrease the reaction rate and zwitterionic micelles can either increase or decrease the rate of ester hydrolysis, depending on the hydrophobicity of the ester and on the reaction conditions. For bimolecular reactions, such as the $\mathrm{OH}^{-}$attack on esters, the second order rate constants for the reaction in water $\left(k_{2 w}\right)$ and micelles $\left(k_{2 m}\right)$ are within one or two orders of magnitude (Romsted 1984). In general, $k_{2 m}$ for $\mathrm{OH}^{-}$ion attack tends to be lower than $\mathrm{k}_{2 \mathrm{w}}$, the inhibition increasing with the hydrophobicity of the ester (Vera \& Rodenas 1986a, b). The reactivity of water attack on esters in micelles is similar to that in bulk water (Kurz 1962; Menger et al 1978).

The effect of micelles on the hydrolysis of the antipyretic, analgesic and anti-inflammatory acetylsalicylic acid (ASA) and on several esters of the local-anaesthetic type has been investigated.

The degradation of ASA exhibits a $\mathrm{pH}$-dependent and a $\mathrm{pH}$-independent region. In the $\mathrm{pH}$-independent region the ionized carboxylate enhances the reaction rate by intramolecular base catalysis (Scheme 2) (Fersht \& Kirby 1967; Connors et al 1986).

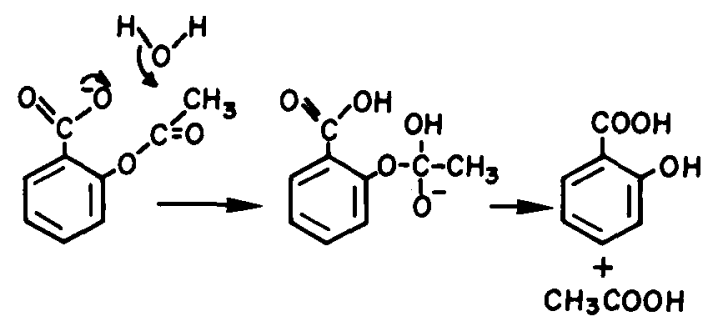

SCHEME 2.

Non-ionic detergents decrease up to twofold the rate of hydrolysis of the undissociated form of ASA (Cid \& Moran 1976; Ismail \& Simonelli 1986). Positively-charged micelles of hexadecyltrimethyl-ammonium bromide (HTAB) inhibit (twofold) the spontaneous decomposition of the ionized form of ASA (Vera et al 1983). This small inhibition has been associated with a decreased availability of water at the reaction site (Broxton 1982). However, there is experimental and theoretical evidence strongly suggesting that at the micellar surface, where ASA is located, water is as reactive as in bulk solution (Kurz 1962; Menger et al 1978; Tanford 1980; Fendler 1982; Israelachvili 1985; Bunton \& Savelli 1986). The shape of the function relating the observed rate constant for $\mathrm{OH}^{-}$attack on ASA with the concentration of positively-charged HTAB is biphasic, the rate increasing with detergent up to a maximum where the rate is higher than in water decreasing thereafter, at higher detergent concentration, to a value lower than that in water (Vera \& Rodenas $1984,1988 \mathrm{a}, \mathrm{b})$. These effects were analysed quantitatively by the PPIE model and the results show that the value of $k_{2 m}$ is one-hundredth that of $\mathrm{k}_{2 \mathrm{w}}$. The rate effects of cationic micelles are strictly dependent on medium composition and salt (Vera \& Rodenas 1984; Rodenas \& Vera 1985).

The reaction of $\mathrm{OH}^{-}$ion with long-chain derivatives of aspirin was used to demonstrate different orientations of substrate with respect to the micellar interface. In micelles, 5alkyl derivatives expose the ester group at the interface and render these derivatives more exposed to $\mathrm{OH}^{-}$ion attack

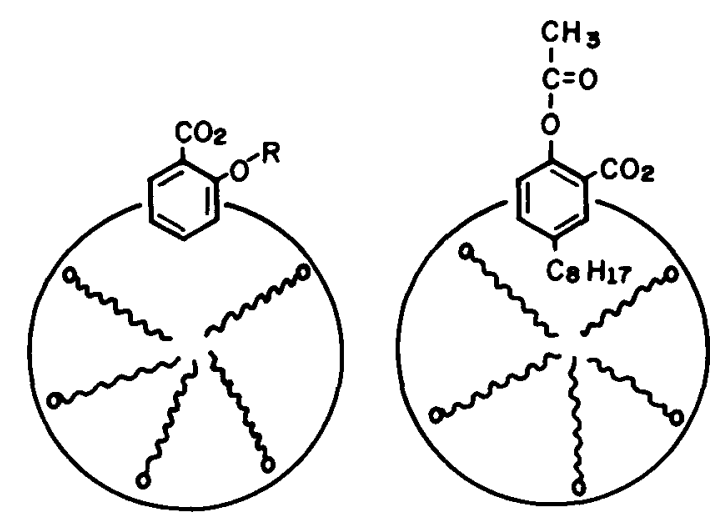

SCHEME 3.

(Broxton et al 1987). NMR analysis of 5-octyl and 5-heptyl derivatives of ASA in micelles shows that the carboxylate group of ASA is perpendicular to the micellar surface and, for the more hydrophobic esters, a change in the relative orientation of the carboxylate and the ester group occurs (Scheme 3) (Broxton et al 1987).

The structural data are consistent with the effect of micelles on the kinetics of the various derivatives. Hydroxylfunctionalized, positively-charged detergents exhibit effects similar to those described for HTAB (Broxton et al 1989).

The effects of micelles on other pharmacologically active esters such as ethyl $p$-aminobenzoate (benzocaine), 2-diethylaminoethyl $p$-aminobenzoate (procaine), and endo- $\alpha$ hydroxy-benzeneacetic 8-methyl-8-azabicyclo-[3,2,1]-oct-3ester (homatropine) have been reviewed up to 1980 (Linda et a) 1981).

Most detergents stabilize local anaesthetics to different extents. Inhibition of the rate of hydrolysis, under different sets of conditions, depends on the detergent charge and drug hydrophobicity (Linda et al 1981). The alkaline degradation of procaine is inhibited by HTAB up to twentyfold at $\mathrm{pH} 9 \cdot 1$, increasing the shelf-life at $25^{\circ} \mathrm{C}$ (Razvi \& Beg 1981, 1982; Razvi et al 1984). Penetration of the drug into the hydrophobic core of the positively charged micelle was suggested as a rationalization of the results. This interpretation is intriguing in view of the amount of data indicating that penetration of substrates, especially substituted phenyl derivatives into the micellar core is by no means a general phenomenon (Broxton et al 1987; Zanette \& Chaimovich 1992). HTAB stabilization of benzocaine in alkaline solutions ( $\mathrm{pH} 10 \cdot 5-12 \cdot 5)$ has also been observed and attributed to poor $\mathrm{OH}^{-}$binding in HTAB (Zarina et al 1986). Binding of $\mathrm{OH}^{-}$ions to $\mathrm{HTAB}$ micelles and local $\mathrm{OH}^{-}$concentration at the micellar surface, has been clearly demonstrated (Chaimovich et al 1979; Quina et al 1980). Procaine and benzocaine are also stabilized by micelles of sodium dodecylsulphate (SDS) and Tween 80 (Razvi \& Beg 1981; Razvi et al 1984). Therefore, while it is clear that micelles increase the stability of local anaesthetics, it is not evident why, especially in the case of positively charged detergents, these watersoluble drugs seem to be compartmentalized differently from $\mathrm{OH}^{-}$ion.

The $\mathrm{pH}$ dependent incorporation of local anaesthetics such as benzocaine, procaine and tetracaine in phospholipid liposomes indicates that the non-dissociated form of the drug 


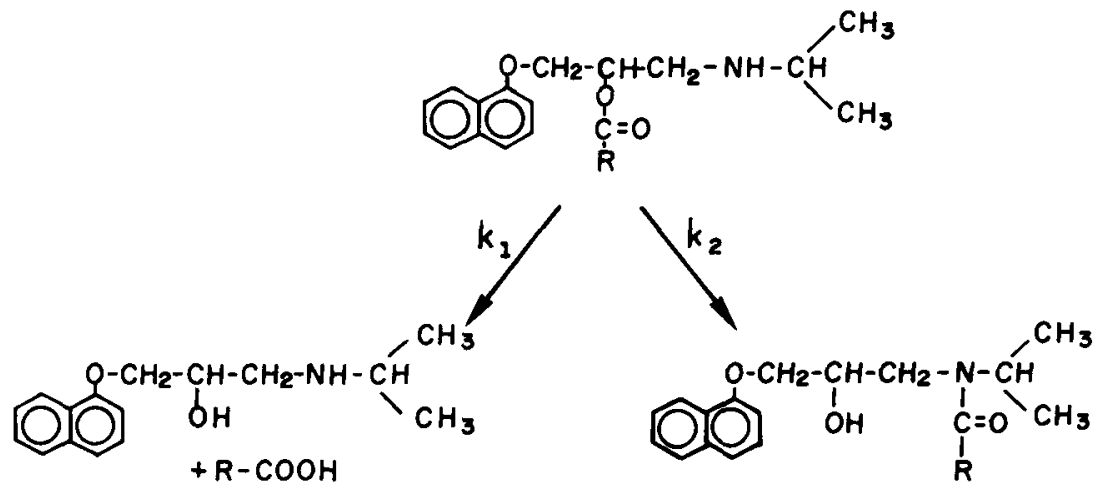

SCHEME 4.

partitions preferentially in the bilayer (Schreier et al 1984; Habib \& Rogers 1987; Bianconi et al 1988). The rate of alkaline hydrolysis of procaine and tetracaine is progressively decreased by liposomes of dimyristoylphosphatidylcholine and dipalmitoylphosphatidylcholine. A maximum protection (by a factor of 2) was obtained with liposomes composed of the negatively charged phosphatidylserine (Bianconi \& Schreier 1991). A two-state model was used to analyse the kinetic results and to propose that the rate of alkaline hydrolysis of the local anaesthetics is negligible when incorporated in the bilayer (Bianconi et al 1988; Bianconi \& Schreier 1991). Quantitative analysis of the effects of bilayers on the $\mathrm{pK}_{\mathrm{a}}$ of local anaesthetics has been described (Schreier et al 1984). The undissociated form of the local anaesthetic is preferentially solubilized in the bilayer and the solubilization site changes upon protonation (Schreier et al 1984; Habib \& Rogers 1987). The alkaline hydrolysis of tetracaine-like local anaesthetics is totally suppressed upon incorporation in zwitterionic bilayers at low ionic strength. This phenomenon has recently been analysed quantitatively, with a two-state model, using electron spin resonance spectroscopy to determine partitioning, orientation and rates of alkaline hydrolysis of a drug analogue (Bianconi \& Schreier 1991).

The effects of neutral (Tween 80, Tergitol), anionic (SDS and sodium taurocholate) and cationic (cetylpyridinium chloride) detergents on the enzyme-catalysed hydrolysis of chloramphenicol stearate have been determined (Bernabei et al 1981). In all cases, rate increases with detergent concentration to a maximum and then decreases at higher concentrations. These results are likely to be due to complex detergent effects on both enzyme activity and antibiotic stability.

The rate of alkaline hydrolysis of acetylcholine is unaffected by neutral micelles (Nakagaki \& Yoroyama 1986a, b). Positively- and negatively-charged micelles, as well as mixtures of ionic with neutral detergents, inhibit the hydrolysis of acetylcholine. Inhibition by SDS is expected, since acetylcholine may bind to negatively charged micelles while $\mathrm{OH}^{-}$ions are largely excluded from the interface, especially at low ionic strength (Quina et al 1982). Positively charged detergents, however, also decrease the rate of acetylcholine hydrolysis probably due to substrate orientiation in the interface. The positively charged group of acetylcholine supposedly lies at the interface while the reaction centre is shielded from $\mathrm{OH}^{-}$attack by insertion in the hydrophobic interior (Nakagaki \& Yoroyama 1986a, b). Thus, for some local anaesthetics and acetylcholine the general rule of rate enhancement of $\mathrm{OH}^{-}$ion attack by positively-charged micelles does not seem to apply. This phenomenon is particularly interesting since in both cases interactions of substituted $\mathrm{N}$ and ester groups with the alkylammonium surface are involved. Understanding the molecular mechanism of this interaction is of interest from both the fundamental and applied points of view.

The decomposition of propranolol esters involves two parallel reactions, namely hydrolysis $\left(k_{1}\right)$ and $O$ to $N$ rearrangement $\left(\mathrm{k}_{2}\right)$ (Scheme 4) (Buur et al 1988; Irwin \& Belaid 1988).

The overall degradation rate is increased up to 30 -fold by a cationic detergent (dodecyltrimethylammonium bromide) and decreased (fivefold) by SDS (Irwin \& Belaid 1988). The rate increase produced by dodecyltrimethylammonium bromide is solely due to catalysis of the intramolecular $\mathrm{O}$ to $\mathrm{N}$ rearrangement. The catalytic effect was rationalized in terms of increased polarization of the carbonyl group in the micelle-bound substrate. The catalytic factor varies from 130 to 530 and depends on substrate hydrophobicity. Anionic detergents, on the other hand, inhibit both the intra- and intermolecular reactions. Although ionic micelles affect the degree of ionization of propranolol esters, this effect was only taken into account to explain the inhibitory effect of SDS (Irwin \& Belaid 1988). Several intramolecular acyl transfers are catalysed by micelles (Cuccovia et al 1977; Oliveira et al 1990). In these, as in other systems, the effect of the interface on the acid dissociation constant of the nucleophile has to be corrected before proposing that the micellar effect is due to an effect on the activation energy of the intramolecular nucleophilic attack (Cuccovia et al 1977; Oliveira et al 1990).

\section{Amides}

The mechanism of amide hydrolysis, involving several potential rate-determining proton transfers, has been the subject of intense research in the last decades. A simplified representation of the mechanism of amide hydrolysis (Jencks 1987) is shown in Scheme 5.

Kinetic effects of non-ionic detergents (ethoxylated lanolin and polysorbate), HTAB and SDS on the alkaline hydrolysis of the anti-inflammatory drug indomethacin (1(4-chlorobenzoyl)-5-methoxy-2-methylindoyl-3-acetic acid) have been described (Dawson et al 1977; Krasowska 1980; Suleiman \& Nagib 1990). Neutral detergents decrease, while 


$$
\begin{aligned}
& \mathrm{RC}-\mathrm{NHR}_{1}+\mathrm{H}_{3} \mathrm{O}+\stackrel{\text { tost }}{\longrightarrow}
\end{aligned}
$$

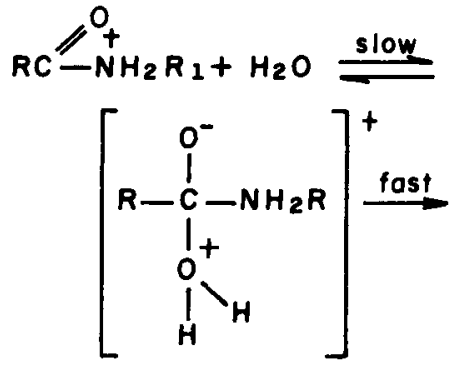

$$
\begin{aligned}
& R C=\stackrel{O}{O_{+}^{+}} H_{2}+R_{1} N_{2} \stackrel{\text { fost }}{\longrightarrow} \\
& R C \stackrel{0}{=} \mathrm{OH}+R_{2} \stackrel{+}{N} H_{3}
\end{aligned}
$$

SCHEME 5.

HTAB increases the reaction rate. Quantitative analysis of this reaction, using a PPIE model, demonstrated that the rate modifications produced by SDS and HTAB can be explained on the basis of reagent concentration and compartmentalization by micelles (Cipiciani et al 1985). Even for the positive detergents, where there is rate increase due to reagent concentration in the micelle, the $\mathrm{k}_{2 \mathrm{~m}}$ is one-twentieth the value for $\mathrm{k}_{2 \mathrm{w}}$ (Cipiciani et al 1985). Inhibition of the alkaline hydrolysis by neutral surfactants increases with the value of the micelle-drug association constant (Lin \& Kawashima 1985). These data are in agreement with the fact that a larger proportion of the ethylene oxide groups in the detergent confer decreased stabilizing power to the surfactants (Lin \& Kawashima 1985). Inhibition seems to be related to the value of the drug-micelle association constant.

The contradiction showing rate decrease by cationic detergents of alkaline decomposition of indomethacin (Suleiman \& Nagib 1990), is apparent only. These authors generalized from results obtained at wa single detergent concentration. Their results are in agreement with previous work showing rate increase at low detergent concentration and decrease at higher concentration (Cipiciani et al 1985).

The decomposition of chlordiazepoxide in aqueous solution is a complex result of two different reaction routes yielding the same products (Scheme 6) (Buur \& Gravsholt 1982).

The reaction pathway includes several ionizable species; therefore, rates and micellar effects are expected to be complex functions of detergent nature and reaction conditions, including $\mathrm{pH}$, ionic concentration and composition (Quina \& Chaimovich 1979; Romsted 1984; Bunton \& Savelli 1986).

Micellar effects of detergents on the stability of clonazepam and chlordiazepoxide as a function of $\mathrm{pH}$ have been described qualitatively under a limited set of experimental conditions (Buur \& Gravsholt 1982; Simonelli et al 1984).

1,4-Benzodiazepinones, exhibiting anxiolytic, anticonvulsant and muscle-relaxing properties have been widely used, especially as these drugs are hydrophobic and display<smiles></smiles><smiles>NCC(Nc1ccc(Cl)cc1C(=O)c1ccccc1)ON</smiles><smiles>NCC(=O)N=C(c1ccccc1)c1cc(Cl)ccc1N</smiles><smiles>CC(C)O</smiles><smiles>C=CCC</smiles><smiles>Nc1ccc(Cl)cc1C(=O)c1ccccc1</smiles><smiles>[CH2+]CC(=O)O</smiles>

SCHEME 6.

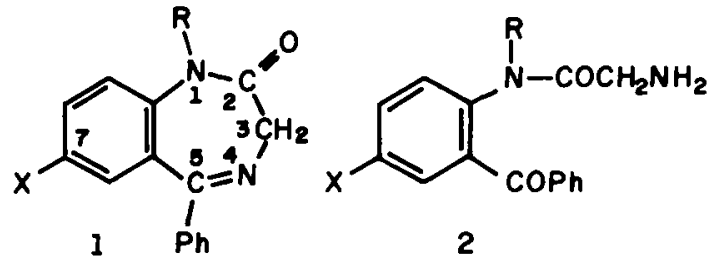<smiles>[R]Nc1ccc([X])cc1C(=NCC(=O)O)c1ccccc1</smiles>

IN ACIDIC SOLUTION

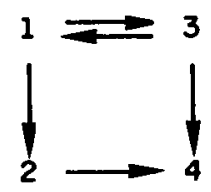

IN BASIC SOLUTION

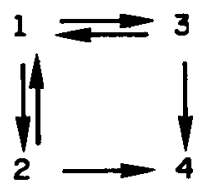

SCHEME 7. interesting decomposition routes (Scheme 7) (Han 1977; Han et al 1977; Broxton \& Wright 1991).

The hydrolysis of 1,4-benzodiazepinones can be initiated by nucleophilic attack at C-5, yielding intermediate 2 or, alternatively, at C-2 with amide hydrolysis producing inter- 

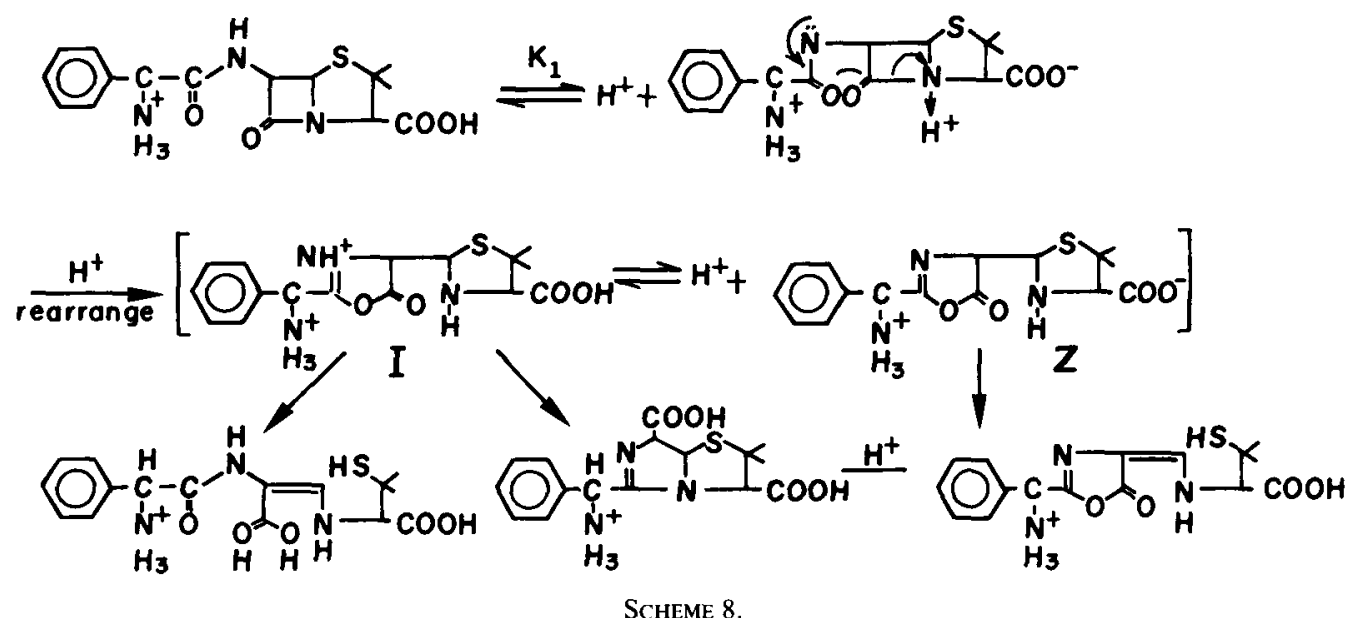

mediate 3. Further decomposition of 2 and 3 yield the same products, namely aminophenazone (4) and glycine (Broxton et al 1984; Broxton \& Morrison 1985; Broxton \& Wright 1986, 1991). Both 2 and 3 can ionize, the relative proportion of the ionic forms determining the major decomposition pathway. In basic solution, 2 does not accumulate due to recyclization (2 to 1) and subsequent decomposition of 2 to yield 4 . In acidic solution, 3 does not accumulate since the reaction from 3 to 1 is reversible and the hydrolysis of 3 is rapid. Water attack at C-2 (amide hydrolysis) is favoured by SDS micelles. For nitrazepam, a change in reaction route from water attack at C-5 to water attack at C-2 was observed upon transferring the reaction site from water to SDS micelles, with no change in reaction rate (Broxton \& Morrison 1985). For $N$-benzyl nitrazepam, however, no change in mechanism was detected; both in water and in SDS micelles, water attack occurred at C-5. The acid-catalysed decomposition of diazepam is inhibited fivefold by SDS micelles (Broxton et al 1984). Changes in the hydrophobicity of the substrate, obtained by $\mathrm{N}$-alkylation of nitrazepam, leads to a relative decrease in the amide hydrolysis and an increase in the azomethine decomposition (Broxton \& Morrison 1985). The basic hydrolysis of nitrazepam involves initial azomethine cleavage (Han 1977; Han et al 1977); however, the rate of reaction is dependent on the hydroxide ion concentration. HTAB increases (tenfold) the rate of alkaline decomposition of diazepam, the reaction involving essentially amide cleavage (Broxton \& Wright 1986). For nimetazepam and $N$-benzylnitrazepam, strong catalysis of amide hydrolysis (100-fold) was observed in HTAB micelles (Broxton \& Wright 1986). HTAOH micelles and dioctadecyldimethylammonium hydroxide vesicles affect the alkaline hydrolysis of benzodiazepines in much the same manner as that described for HTAB micelles (Broxton et al 1988).

Recently, Broxton \& Wright (1991) have reinvestigated the mechanism of hydrolysis of oxazepam and 2 -methyldiazepam in water and in the presence of micelles (Scheme 7). In dilute acid $(<0.2 \mathrm{M})$ the reaction pathway is mostly azomethine cleavage. Upon increasing the acid concentration, amide hydrolysis prevails. SDS micelles favour the amide hydrolysis route, presumably by concentrating $\mathrm{H}^{+}$at the micellar surface. In alkali, the route for oxazepam hydrolysis is also dependent on the $\mathrm{OH}^{-}$ion concentration and the effect of
HTAB is dependent on the relative $\mathrm{OH}^{-}$concentration (Broxton \& Wright 1991). Addition of a 2-methyl group (2'methyl diazepam) produces a mechanistic effect similar to that observed for the alkaline hydrolysis of diazepam with HTAB micelles (Broxton et al 1984).

Quantitative analysis of micellar effects on the hydrolysis of bromazepam, flunitrazepam and diazepam has recently been attempted. In all cases, the drug-micelle association constant increases by increasing either the hydrophobicity of the drug or the chain length of the surfactant (Moro et al 1991). However, the kinetic effects are independent of the association constant of the drug, suggesting no changes in reaction sites upon increasing the drug-micelle association constant. Non-ionic detergents and cationic detergents exert negligible kinetic effects on the rate of acid hydrolysis while anionic micelles inhibit the degradation by up to 40 -fold (Moro et al 1991).

\section{B-Lactam Antibiotics}

Catalysis and inhibition of the acid-catalysed hydrolysis of propicillin and cefazolin by SDS and HTAB are as expected from coulombic concentration or repulsion of $\mathrm{H}^{+}$ion (Tsuji et al 1978, 1982). The three- to fourfold stabilization by HTAB and destabilization by SDS were obtained at $0.15 \mathrm{M}$ salt (Tsuji et al 1978, 1981, 1982). At this ionic concentration, added salt displaces $\mathrm{H}^{+}$or $\mathrm{OH}^{-}$from the micellar surface; therefore, modest micellar effects on rates are expected (Bunton \& Savelli 1986; Fendler 1982). The neutral detergent polyoxyethylene-23-lauryl ether inhibits the acid degradation of both $\beta$-lactam antibiotics. The rate of hydrolysis of the protonated form of propicillin is not influenced by micelles (Tsuji et al 1981, 1982). It is probable that the very water-soluble propicillin does not bind to micelles even at high detergent concentration.

The oxazolone intermediate, produced upon acid hydrolysis of $\alpha$-aminobenzylpenicillin (ampicillin), can be zwitterionic or positively charged. The zwitterionic intermediate leads to penicillenic acid while the positively-charged intermediate produces penalmadic acid (Scheme 8) (How \& Poole 1969).

An aqueous acid, as determined by repetitive spectral data, penicillenic acid predominates in the initial reaction mixtures (Ortega et al 1984). SDS micelles increase the rate of 


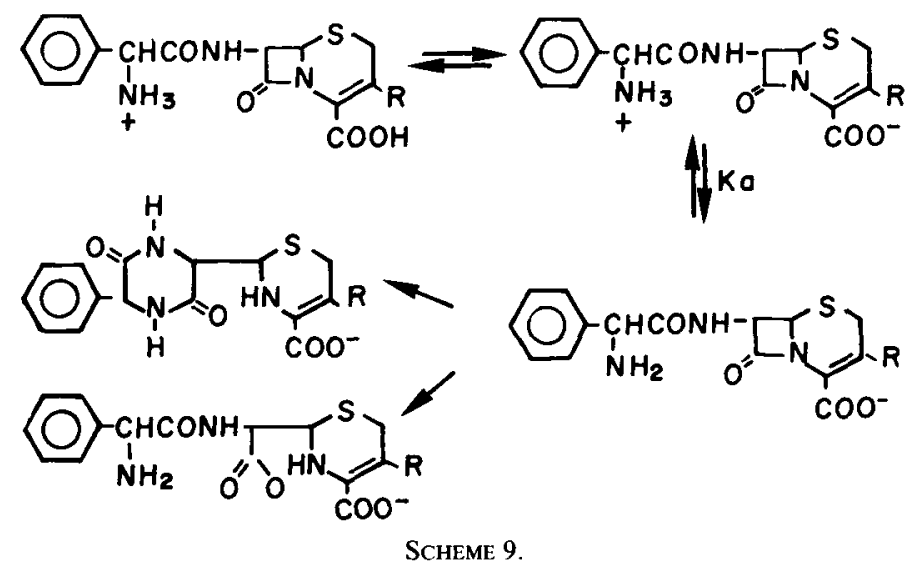

acid hydrolysis of ampicillin and since the negativelycharged aggregate stabilizes the positively-charged form, the main reaction product in SDS is penicillenic acid (Ortega et al 1984). In spite of the observation that the second-order rate constants in the micelles are, in general, similar to those in water, micelles often modify the product composition of substrates reacting by more than one route. Modifications of product composition usually reflect the preferred interaction of transition states (or intermediates) along one of the pathways in the reaction manifold with the micellar headgroups (Politi \& Chaimovich 1991).

The effect of detergents upon the rate of hydrolysis of benzylpenicillin has been analysed in some detail (Gensmantel \& Page 1982a, b; Chaimovich et al 1985). The rate increase produced by HTAB was attributed exclusively to micellar concentration, the intrinsic reactivity being similar in the micelle and in the aqueous phase (Chaimovich et al 1985).

The interactions of cephalosporins with micelles are complicated since these drugs can exist in solution in several ionic forms; therefore drug micelle interactions are very sensitive to $\mathrm{pH}$ changes (Tsuji et al 1978, 1981, 1982; Nakashima et al 1985; Oliveira et al 1990). Cephalosporins can decompose inter- or intramolecularly (Scheme 9) (Cohen et al 1973; Bundgaard 1976a, b, 1977; Yapana \& Tsuji 1976; Dinner 1977; Indelicato et al 1977; Tsuji et al 1981).

The intramolecular reaction must proceed via the cis conformation of the amide bond (Scheme 10) (Oliveira et al 1991). Under conditions where presumably the intramolecular reaction is dominant, HTAB and benzalkonium chloride catalyse and SDS inhibits the decomposition of cephalexin (Yashuara et al 1977).

Controlled studies of micellar effects on the decomposition of $\alpha$-aminophenylcephalosporins showed that positivelycharged micelles increase the rate of $\mathrm{OH}^{-}$ion attack (Scheme .9), essentially by concentrating both species in the micelle (Oliveira et al 1990, 1991). PPIE analysis of micellar effects on the decomposition of $\alpha$-aminophenylcephalosporins was carried out over a range of salt concentrations and $\mathrm{pH}$ values (Oliveira et al 1990). Judicious selection of reaction conditions, i.e. choice of buffers and salt concentrations, allowed the quantitative description of detergent effects over a wide range of $\mathrm{pH}$ and micelle concentrations (Oliveira et al 1990). That work, and others, constitute examples of how the application of known models for quantitative analysis of

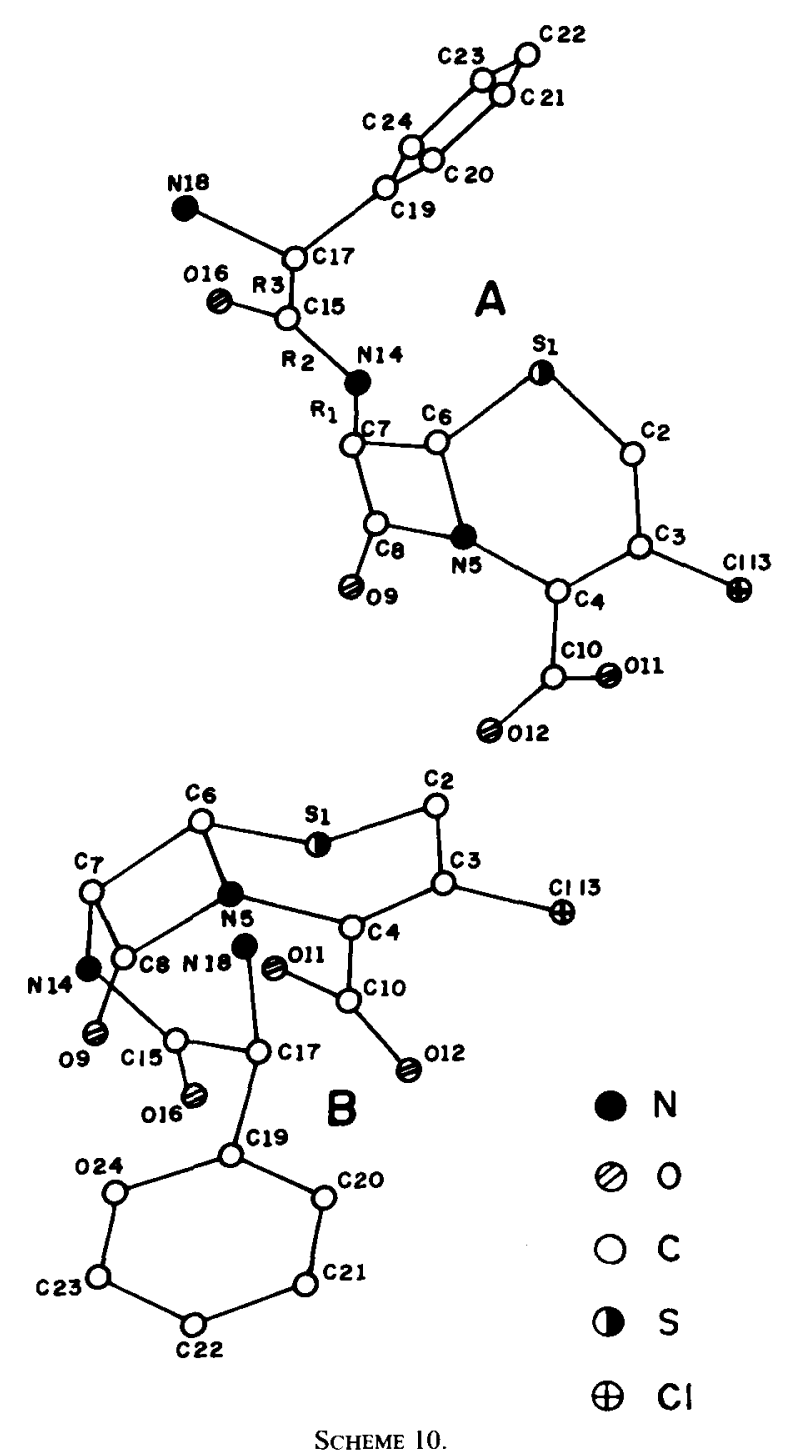

micellar effects on reaction rates can be used to analyse, as well as to predict, the effect of a given detergent on the stability of a drug.

The intramolecular decomposition of cefaclor is catalysed by HTAB, Brij-35 and micelles of the zwitterionic detergent 
3-( $N$-dodecyl- $N, N^{\prime}$-dimethylammonium) propane-1-sulphonate (Oliveira et al 1991). The effect of micelles on the intramolecular decomposition of cefaclor was attributed to the stabilization of the reactive conformation of the antibiotic (Scheme 10). Recent studies of temperature effects on this reaction are in agreement with the proposal for a micellar-induced conformer stabilization (Oliveira \& Chaimovich, unpublished).

\section{Other Functions and Applications}

The acid-catalysed hydrolysis of epoprostenol, an analogue of 6-ketoprostaglandin $F_{1 x}$, is inhibited by HTAB up to 1600 fold (Cho 1982). Since these results were obtained at $0.5 \mathrm{M}$ salt concentration and at a single detergent concentration, it is possible that HTAB, at different concentrations and lower salt, can increase the stability of epoprostenol to a much larger extent.

The rate of electron transfer from $\mathrm{Fe}^{3+}$ to $\mathrm{N}$-methylphenothiazine decreases in the presence of HTA nitrate. Quantitative analysis of the results using a PPIE model, indicate high drug-micelle association constants (Minero et al 1983). The positively charged HTA nitrate can inhibit electron transfer to the micelle-solubilized drug, presumably by excluding the $\mathrm{Fe}^{3+}$ ion from the interface. With SDS micelles the rates of electron transfer reach a maximum in the region of the critical micelle concentration (CMC). In this latter case the detergent effect was attributed, qualitatively, to hydrophobic and coulombic interactions (Minero et al 1983).

Micellar effects on the stability of several radical cations of pharmaceutical relevance have been investigated (Nencova et al 1986; Carlotti et al 1987). Cationic and neutral surfactants below the CMC display no effects on the stability of phenothiazine, diethazine and chlorpromazine radical cations. The same detergents accelerate the decay above the CMC (Nencova et al 1986). The decomposition of radical cations is catalysed by SDS below the CMC and strongly inhibited at higher detergent concentrations. Qualitative analysis suggests that coulombic interactions between aggregates, $\mathrm{H}^{+}$ion and cation radicals are responsible for the observed effects (Nencova et al 1986). The stability of cation radicals from chlorpromazine is reduced by bile salts. PPIE analysis of the data suggests that the effect may arise from substrate concentration in the micelles (Carlotti et al 1987).

The photochemical reactivity of chlorpromazine with oxygen is substantially modified in micelles (Epling et al 1983). The photodehalogenation in micelles is the predominant photodecomposition route while photo-oxidation, prevalent in aqueous solution, is totally blocked by positive, negative and neutral micelles (Enever et al 1979). Quenching by oxygen is reduced in many organized systems (Turro \& Aikawa 1979). However, the total inhibition of chlorpromazine photo-oxidation by oxygen may be the result of a series of factors including decreased quenching rates, faster abstraction of neighbouring hydrogens and increased efficiencies of photodehalogenation routes (Enever et al 1979).

Doxorubicin and its derivatives are glycosidic anthracyclins which decompose by hydrolysis of the glycosidic linkage yielding an aminosugar and the corresponding aglycone (Scheme 11) (Bekers et al 1989).

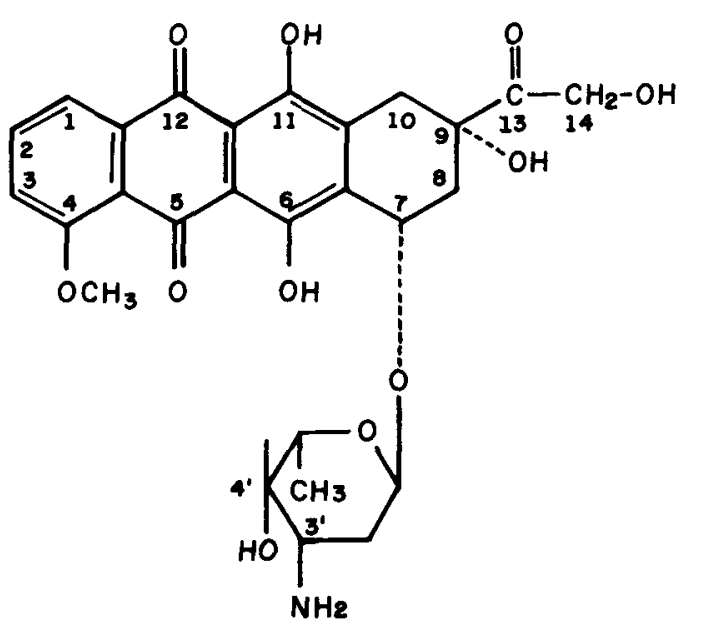

SCHEME 11.

Mixed liposomes of phosphatidyl choline and phosphatidylserine stabilize a derivative of $N$-trifluoroacetyldoxorubicin-14-valerate for more than a year (Bekers et al 1989). Although promising, these results are not of immediate utility since the system was studied under a very restricted set of conditions.

Some data on microemulsion-based insulin treatment suggests that the biological stability of insulin in-vivo may change in microemulsions (Patel et al 1991).

There are several other examples where the effect of surfactants on drug stability in pharmaceutical preparations has been described (Amin \& Bryan 1973; Naggar et al 1974; Oppenheim 1976; Aboutaled et al 1985; Aguiar \& Rasadi 1982). The complexity of some of these preparations, however, is such that it is difficult to interpret the results solely on the basis of surfactant effects on drug stability.

Several compounds of therapeutic use can associate spontaneously in solution to form aggregates (Attwood et al 1974; Attwood \& Udeala 1975a, b; Ong \& Kostenbauder 1975; Attwood 1976; Thoma \& Siemer 1976a, b; Attwood \& Gibson 1978, Attwood \& Tolley 1980; Anderson et al 1983, 1985; Attwood \& Natarajan 1983; Maidanov et al 1983; Attwood \& Agarwal 1984; Carlotti et al 1984; Thoma \& Albert 1983; Hidaka et al 1986; Attwood \& Fletcher 1987; Shimizu \& Kambe 1988; Thoma \& Herzfeldt 1988a, b; Thoma \& Kasper 1988). Self-association of drugs in aqueous solution can profoundly modify the properties of the pharmaceutical formulation, leading to a variety of effects including change in bioavailability, masking of biological effects and differential drug stability. Several studies suggest that the chemical reactivity of the aggregated drugs is different from that of the monomeric forms. The micellization of penicillin $\mathrm{G}$ increases the rate of acid hydrolysis of the drug up to three times while the alkaline degradation pathway is inhibited by $50 \%$ (Ong \& Kostenbauder 1975). Decrease in reactivity upon self-association of flupenthixol (Enever et al 1979), clopenthixol (Thoma \& Albert 1983) and methylprednisolone (Anderson et al 1985) has also been documented. The self-association-related stabilization depends on the hydrophobicity of the drug monomer. Increases of 6-, 15- and 32-fold in stability have been 
reported for succinate, adipate and suberate methylprednisolone-21-hemiesters, respectively (Anderson et al 1983). Micellization of both charged and uncharged forms of the local anaesthetic tetracaine and some analogues leads to changes in the rates of hydrolysis (Schreier et al 1986). The properties of drug aggregates can be compared with those of detergent aggregates; therefore, it would be useful if the properties of the aggregates were analysed quantitatively to the extent now possible with the micellar presented above.

Another field in which supramolecular aggregates have found a widespread application is analytical chemistry. Among other advantages, micelles and other amphiphile aggregates avoid the use of organic solvents, increase the sensitivity of luminescence methods, shift spectra of reagents or products, concentrate reagents in a small reaction volume, incorporate water insoluble reagents and serve as an efficient separation medium in several chromatographic applications (Hinze 1979). Since a thorough analysis of this field is not within the scope of this review, we mention just one application of the use of micelles in analytical pharmaceutical chemistry. Addition of surfactants to acid solutions of benzodiazepines modifies the position of the absorption bands of the hydrolytic products allowing simultaneous determination of binary mixtures (De la Guardia et al 1989).

\section{Conclusion}

Micelles, and other supramolecular aggregates, can profoundly affect the stability of drugs in pharmaceutical preparations. The effect of micelles on drug stability can be analysed quantitatively under a wide variety of conditions. Current models allow the analysis of drug incorporation as well as separate intrinsic reactivities in the bulk phase from that in the aggregate. This analysis is necessary both to understand the effect of the aggregate on the lifetime and pharmacological effects of the product, and to predict the effects of detergent-like additives on the properties of the pharmaceutical preparation.

\section{Acknowledgements}

This work was supported by the following Brazilian agencies: FAPESP (Projeto Temático), FIMEP (PADCT-Quimica), CNPq (Projeto Integrado) and CAPES (PICD to AGO). The authors thank Dr Mari Armelin for her help with the manuscript and Dr Iolanda M. Cuccovia for discussions.

\section{References}

Aboutaled, A. E., Mesiha, M. S., Abdel-Zaher, A. (1985) Formulation and stability study of certain mixtures containing solubilized methotrimeprazine. Pharm. Ind. 47: 1295-1298

Aguiar, A. J., Rasadi, B. (1982) Levonantradol and $N$-methyl levonantradol formulations. Eur. Pat. Appl. EP 56,681

Almgren, M., Aniansson, E. A. G., Wall, S. N., Holmaker, K. (1977) On the kinetics of redistribution of micellar sizes. In: Mittal, K. L. (ed.) Micellization, Solubilization and Microemulsions. Plenum Press, New York, pp 329-346

Amin, M. I., Bryan, J. T. (1973) Kinetics and factors affecting stability of methylprednisolone in aqueous formulation. J. Pharm. Sci. 62: 1768-1771

Anderson, B. D., Conradi, R. A., Johnson, K. (1983) Influence of premicellar and micellar association on the reactivity of methyl prednisolone 21 -hemi esters in aqueous solution. J. Pharm. Sci. 72: $448-454$
Anderson, B. D., Conradi, R. A., Knuth, K. E., Nail, S. L. (1985) Strategies in the design of solution-stable, water-soluble prodrugs II: properties of micellar prodrugs of methylprednisolone. J. Pharm. Sci. 74: 375-381

Attwood, D. (1976) Aggregation of antiacetylcholine drugs in aqueous solution: monomer concentrations in non-micellar drug systems. J Pharm. Pharmacol. 28: 762-765

Attwood, D., Agarwal, S. P. (1984) Light scattering studies on micelle formation by some penicillins in aqueous solution. $J$. Pharm. Pharmacol. 36: 563-564

Attwood, D., Fletcher, P. (1987) Total intensity and quasielastic light scattering studies on the association of amphiphilic drugs in aqueous electrolyte solution. J. Coll. Int. Sci. 115: 104-109

Attwood, D., Florence, A. T. (1983) Surfactants Systems. Their Chemistry, Pharmacy and Biology. Chapman \& Hall, London, pp 739-748

Attwood, D., Gibson, J. (1978) Aggregation of antidepressant drugs in aqueous solution. J. Pharm. Pharmacol. 30: 176-180

Attwood, D., Natarajan, R. (1983) Micellar properties of chlorpromazine hydrochloride in concentrated electrolyte solutions. J. Pharm. Pharmacol. 35: 317-319

Attwood, D., Tolley, J. A. (1980) Self-association of analgesics in aqueous solution: micellar properties of dextropropoxyphene hydrochloride and methadone hydrochloride. J. Pharm. Pharmacol. 32: 533-536

Attwood, D., Udeala, O. K. (1975a) Aggregation of antihistamines in aqueous solution. The effect of electrolyte on the micellar properties of some diphenylmethane derivatives. J. Pharm. Pharmacol. 27: 395-399

Attwood, D., Udeala, O. K. (1975b) The surface activity of some antihistamines at the air-solution interface. J. Pharm. Pharmacol. 27: $754-758$

Attwood, D., Florence, A. T., Gillan, J. M. N. (1974) Micellar properties of drugs: properties of micellar aggregates of phenothiazines and their aqueous solutions. J. Pharm. Sci. 6: 988-993

Baptista, M. S., Cuccovia, I., Chaimovich, H., Politi, M. J., Reed, W. F. (1992) Electrostatic properties of zwitterionic micelles. J. Phys. Chem. 96: 6442-6449

Bekers, O., Beijnen, J. H., Storm, G., Bult, A., Underberg, W. J. M. (1989) Chemical stability of $N$-trifluoroacetyl doxorubicin-14valerate (AD-32) in aqueous media after liposome encapsulation. Int. J. Pharm. 56: 103-109

Bernabei, M. T., Coppi, G., Cameroni, R. (1981) Influence of surfactants on the in vitro enzymatic hydrolysis of chloramphenicol stearate. Farm. Ed. Prat. 36: 294-303

Bianconi, M. L., Schreier, S. (1991) EPR study of membrane partitioning, orientation, and membrane-modulated alkaline hydrolysis of a spin labelled benzoic acid ester. J. Phys. Chem. 95 2483-2486

Bianconi, M. L., Amaral, A. T., Schreier, S. (1988) Use of membrane spin label spectra to monitor rates of reaction of partitioning compounds: hydrolysis of a local anesthetic analog. Biochem. Biophys. Res. Commun. 152: 344-350

Broxton, T. J. (1982) Micellar catalysis of organic reactions. VIII. Kinetic studies of hydrolysis of 2-(acetyloxy) benzoic acid (aspirin) in the presence of micelles. Aust. J. Chem. 35: 1357-1363

Broxton, T. J., Morrison, S. R. (1985) Micellar catalysis of organic reactions XVII. Hydrolysis of nitrazepam and some $\mathrm{N}$-alkylated derivatives. Aust. J. Chem. 38: 1037-1043

Broxton, T. J., Wright, S. (1986) Micellar catalysis of organic reactions. 18. Basic hydrolysis of diazepam and some $\mathrm{N}$-alkylderivatives of nitrazepam. J. Org. Chem. 51: 2965-2969

Broxton, T. J., Wright, S. (1991) Micellar catalysis of organic reactions. XXX. A study of the mechanism of hydrolysis of oxazepam and 2'-methyldiazepam in the presence of micelles and in water. Aust. J. Chem. 44: 103-111

Broxton, T. J., Christie, J. R., Sango, X. (1987) Micellar catalysis of organic reactions. 20 . Kinetics studies of the hydrolysis of aspirin derivatives in micelles. J. Org. Chem. 52: 4814-4817

Broxton, T. J., Christie, J. R., Sango, X. (1989) Micellar catalysis of organic reactions. 25. Orientational effects in hydroxyfunctionalized micelles. J. Org. Chem. 54: 1919-1922

Broxton, T. J., Ryan, T., Morrison, S. R. (1984) Micellar catalysis of 
organic reactions. 14. Hydrolysis of some 1.4-benzodiazepin-2one drugs in the acid solution. Aust. J. Chem. 37: 1895-1902

Broxton, T. J., Sango, X., Wright, S. (1988) Micellar catalysis of organic reactions. 22. A comparison of the benzodiazepinones in the presence of reactive counterion micelles and vesicles. Can. J. Chem. 66: 1566-1570

Bruice, T. C., Benkovic, S. J. (1966) Bioorganic Mechanisms. W. A. Benjamin, New York.

Bundgaard, H. (1976a) Chemical studies related to cephalosporin allergy II. Competitive amine catalyzed intra- and intermolecular aminolysis of cephalexin and cephaloglycin in aqueous solution. Acta Pharm. Suec. 13: 299-312

Bundgaard, D. H. (1976b) Hydrolysis and intramolecular aminolysis of cephalexin and cephaloglycin in aqueous solution. Arch. Pharm. Chem. Sci. Ed. 4: 25-43

Bundgaard, H. (1977) Isolation and characterization of cephalexin degradation products formed in neutral aqueous solution. Arch. Pharm. Chem. Sci. Ed. 5: 49-55

Bunton, C. A., Savelli, G. (1986) Organic reactivity in aqueous micelles and similar assemblies. Adv. Phys. Org. Chem. 22: 213309

Buur, A., Gravsholt, S. (1982) Solubility and stability of chlordiazepoxide in aqueous detergent solutions. Arch. Pharm. Chem. Sci. Ed. 10: $1-16$

Buur, A., Bundgaard, H., Lee, V. H. L. (1988) Prodrugs of propranolol: hydrolysis and intramolecular aminolysis of various propranolol esters and an oxazolidin-2-one derivative. Int. J. Pharm. 42: 51-60

Carlotti, M. E., Trota, M., Gasco, M. R. (1984) Behavior of barbituric acids towards phenothiazine drugs. Pharm. Acta Helv. 59: $25-28$

Carlotti, M. E., Gasco, M. R., Trota, M. (1987) The influence of the bile salts aggregates on the kinetics of chlorpromazine cation radical decay. Pharm. Acta Helv. 62: 183-187

Chaimovich, H., Bonilha, J. B. S., Politi, M. J., Quina, F. H. (1979) Ion exchange in micellar solution. 2. Binding of hydroxide ion to positive micelles. J. Phys. Chem. 83: 1851-1854

Chaimovich, H., Correia, V. R., Araujo, P. S., Aleixo, R. M., Cuccovia, 1. M. (1985) A quantitative analysis of the effect of hexadecyltrimethylammonium bromide micelles on the alkaline hydrolysis of benzylpenicillin. J. Chem. Soc. Perkin Trans. II: 925-928

Cho, M. J. (1982) Reduced hydrolytic lability of epoprostenol in the presence of cationic micelles. J. Pharm. Sci. 71: 453-454

Cid, E., Moran, I. (1976) Efecto de los tensioativos no ionicos em la velocidad de hidrolisis del acido acetil salicilico en suspension. Farm. Ed. Prat. 31: 88-94

Cipiciani, A., Ebert, C., Germani, R., Lovtecich, M., Rubessa, F. Savelli, G. (1985) Micellar effects on the basic hydrolysis of indomethacin and related compounds. J. Pharm. Sci. 74: 11841187

Cohen, A. I., Funke, P. T., Puar, N. M. S. (1973) Alkaline degradation product of cephradine. J. Pharm. Sci. 62: 1559-1561

Connors, K. A., Amidon, G. L., Stella, V. J. (1986) Chemical Stability of Pharmaceuticals. 2nd edn, John Wiley, New York

Correia, V. R., Cuccovia, I. M., Chaimovich, H. (1991) Effect of hexadecyltrylammonium bromide micelles on the hydrolysis of substituted benzoate esters. J. Phys. Org. Chem. 4: 13-18

Cuccovia, I. M., Schroeter, E. H., Baptista, R. C., Chaimovich, H (1977) Effect of detergents on the $\mathbf{S}$ to $\mathbf{N}$ transfer of $S$-acylmercaptoethylamines. J. Org. Chem. 42: 3400-3403

Dawson, J. E., Hajratwala, B. R., Taylor, H. (1977) Kinetics of indomethacin degradation II. Presence of alkali plus surfactant. $\mathrm{J}$. Pharm. Sci. 66: 1259-1263

De la Guardia, M., Galdu, M. R., Monzo, J., Salvador, A. (1989) Simultaneous determination of benzodiazepines by ultravioletvisible spectrophotometry in micellar media. Analyst 114: 509512

Dinner, A. (1977) Cephalosporins degradations. J. Med. Chem. 20: 963-965

El-Nokaly, M., Friberg, S. E. (1982) Microemulsions. Cosmet. Toilet. 97: 55-62

Enever, R. P., Li Wan Po, A., Shotton, E. (1979) Flupenthixol dihydro chloride decomposition in aqueous solution. J. Pharm. Sci. 68: 169-171

Epling, G. A., Black, C., Rawal, V. (1983) Photochemistry in micelles as a model for the in vivo phototoxicity of chlorpromazine. J. Chem. Soc. Perkin Trans. II 9: 1313-1316

Fendler, J. H. (1982) Membrane Mimetic Chemistry. Wiley-Interscience, New York

Fersht, A. R., Kirby, A. J. (1967) The hydrolysis of aspirin. Intramolecular general base catalysis of ester hydrolysis. J. Am. Chem. Soc. 89: 4857-4863

Gasco, M. R., Gallarate, M., Pattarino, F. (1988a) Behaviour of doxorubicin in o/w microemulsions. Farm. Ed. Prat. 43: 3-12

Gasco, M. R., Pattarino, F., Voltani, I. (1988b) On release of prednisone from oil in water microemulsions. Farm. Ed. Prat. 43: $325-350$

Gensmantel, N. P., Page, M. I. (1982a) The micelle-catalyzed hydrolysis of benzylpenicillin. J. Chem. Soc. Perkin Trans. II 2: 147-154

Gensmantel, N. P., Page, M. I. (1982b) The effect of increasing the hydrophobicity of penicillin on its micelle-catalyzed hydrolysis. J. Chem. Soc. Perkin Trans. II 2: 155-159

Gibaldi, M., Feldman, S. (1970) Mechanism of surfactant effects on drug absorption. J. Pharm. Sci. 59: 579-589

Habib, M. J., Rogers, I. A. (1987) Stabilization of local anesthetics in liposomes. Drug. Dev. Ind. Pharm. 13: 1947-1971

Han, W. W. (1977) Kinetics and mechanism of hydrolysis of 1,4 benzodiazepines. II:Oxazepan and diazepam. J. Pharm. Sci. 66: $573-577$

Han, W. W., Yakatan, G. J., Maness, D. D. (1977) Kinetics and mechanism of hydrolysis of 1,4-benzodiazepines. J. Pharm. Sci. 66: 795-798

Hidaka, H., Onai, T., Murata, M., Ishii, T., Gratzel, M. (1986) Studies of alkylphenothiazine sulfonate micellar assemblies in aqueous solution. J. Chem. Soc. Faraday Trans. I 82: 2615-2620

Hinze, W. L. (1979) Use of surfactant and micellar systems in analytical chemistry. In: Mittal, K. L. (ed.) Solution Chemistry of Surfactants. Vol. 1. Plenum, New York, pp 79-128

How, J. P., Poole, J. W. (1969) Kinetics and mechanisms of degradation of ampicillin in solution. J. Pharm. Sci. 58: 447-454 Indelicato, J. M., Dinner, A., Peters, L. R., Whilham, W. L. (1977) Hydrolysis of 3-chloro-3-cephens. Intramolecular nucleophilic attack in cephaclor. J. Med. Chem. 20: 961-963

Irwin, W. J., Belaid, K. A. (1988) Drug delivery by ion exchange. Stability of ester prodrugs of propranolol in surfactant and enzymatic systems. Int. J. Pharm. 48: 159-166

Ismail, S., Simonelli, A. P. (1986) Kinetics of aspirin hydrolysis in aqueous solution of surfactants $I$ : nonionic surfactants. Bull. Pharm. Sci. (Assiut Univ.) 9: 119-136

Israelachvili, J. N. (1985) Intermolecular and Surface Forces. Academic Press, London

Jayakrishnan, A., Kalaiarasi, K., Shah, D. O. (1983) Microemulsions: evolving technology for cosmetic applications. J. Soc. Cosmet. Chem. 34: 335-350

Jencks, W. P. (1987) Catalysis in Chemistry and Enzymology. Dover, New York

Kawamuro, M. K., Chaimovich, H., Abuin, E. B., Lissi, E. A., Cuccovia, I. M. (1991) Evidence that the effects of synthetic amphiphile vesicles on reaction rates depend on vesicle size. $\mathbf{J}$. Phys. Chem. 95: 1458-1463

Keipert, S., Siebenbrodt, I., Luders, F., Bornschein, M. (1989) Mikroemulsionen und ihre potentielle pharmazeutische Nutzing. Pharmazie 44: 433-444

Knight, C. G. (1981) Liposomes from Physical Structure to Therapeutic Applications. Elsevier, Amsterdam

Krasowska, H. (1980) Effect of chemical structure of some nonionic surfactants on the alkaline hydrolysis of indomethacin. Pharm. Ind. 42: 852-854

Kurz, J. L. (1962) Effects of micellization on the kinetics of the hydrolysis of monoalkyl sulfates. J. Phys. Chem. 66: 2239-2249

Lin, S. Y., Kawashima, Y. (1985) Kinetic studies on the stability of indomethacin in alkaline aqueous solution containing polyoxyethylene-polyoxypropylene surface active block polymer. Pharm. Acta Helv. 60: $345-350$ 
Linda, P., Rubessa, F., Savelli, G. (1981) Reactivity of drugs in the presence of surface-active agents. Chim. Ind. (Milan) 63: 333-338

Lissi, E., Abuin, E., Ribot, G., Valenzuela, E., Chaimovich, H., Araujo, P. S., Aleixo, R. M. V., Cuccivia, I. M. (1985) Ion exchange between $n$-alkyl carboxylates and bromide at surface of cetyltrimethylammonium bromide micelles. J. Coll. Int. Sci. 103 139-144

Lissi, E., Abuin, E., Cuccovia, I. M., Chaimovich, H. (1986) Ion exchange between alkyl dicarboxylates and hydrophilic anions at the surface of cetyltrimethylammonium micelles. J. Colloid Interf. Sci. 112: 513-519

Maidanov, V. V., Egutkin, N. L., Nikitin, Y. E. (1983) Surfactant properties of some antibiotics. Antibiotiki (Moscow) 28: 663-665

Martinek, K., Yatsimirski, A. K., Levashov, A. V., Berezin, I. V. (1977) The kinetic theory and the mechanism of micellar effects on the chemical reactions. In: Mittal, K. L. (ed.). Micellization, Solubilization, and Microemulsions. Plenum Press, New York, pp 489-508

Martini, M. C., Bobin, M. F., Flandin, H., Caillaud, F., Cotte, J. (1984) Role des microemulsions dans l'absorption percutanee de tocopherol. J. Pharm. Belg. 34: 348-354

Menger, F. M., Jerkunica, M., Jhonston, J. C. (1978) The water content of a micelle interior. The Fjord vs. Reef models J. Phys. Chem. 100: 4676-4678

Minero, C., Pramuro, E., Pelizzetti, E., Meisel, D. (1983) Oneelectron transfer equilibrium and kinetics of $N$-methylphenothiazine in micellar systems. J. Phys. Chem. 87: 399-407

Moro, M. E., Novillo-Fertrell, J., Velazquez, M. M., Rodriguez, J. (1991) Kinetics of the acid hydrolysis of diazepam, bromazepam, and flunitrazepam in aqueous and micellar systems. J. Pharm. Sci. 80: 459-468

Naggar, V., Daabis, N. A., Motawi, M. N. (1974) Effect of solubilizers on the stability of tetraxyline. Pharmazie 29: 126-129

Nakagaki, M., Yoroyama, S. (1986a) Base-catalyzed hydrolysis of acetylcholine in the presence of cationic and nonionic surfactants. Bull. Chem. Soc. Jpn. 59: 19-23

Nakagaki, M., Yoroyama, S. (1986b) Base-catalyzed hydrolysis of acetylcholine in the presence of anionic and nonionic surfactants. Bull. Chem. Soc. Jpn. 59: 1925-1930

Nakashima, E., Tsuji, A., Nakamura, M., Yamana, T. (1985) Physicochemical properties of amphoteric beta-lactam antibiotics. IV. First and second-order degradations of cephaclor and cefatrizine in aqueous solution and kinetic interpretation of intestinal absorption and degradation of the controlled antibiotics. Chem. Pharm. Bull. (Tokyo) 33: 2098-2106

Nencova, I., Novotny, J., Horska, V. (1986) Spectrophotometric study of phenothiazine derivatives and their cation radicals in micellar media. Microchem. J. 34: 180-189

Ong, J., Kostenbauder, H. B. (1975) Effect of self-association on the rate of penicillin $G$ degradation in concentrated solutions. $J$. Pharm. Sci. 64: 1378-1380

Oliveira, A. G., Cuccovia, I. M., Chaimovich, H. (1990) Micellar modification of drug stability. Analysis of the effect of hexadecyl trimethylammonium halides on the rate of degradation of cephaclor. J. Pharm. Sci. 79: 37-42

Oliveira, A. G., Nothenberg, M. S., Cuccovia, I. M., Chaimovich, H (1991) Micellar catalysis of the intramolecular aminolysis of the beta-lactam antibiotic cephaclor. J. Phys. Org. Chem. 4: 19-24

Oppenheim, R. C. (1976) Surfactants and micelles in pharmaceutical formulations. Aust. J. Pharm. Sci. NS5: 11-16

Ortega, F., Vera, S., Rodenas, E., Cachaza, J. M. (1984) Effect of sodium lauryl sulfate micelles on the acid hydrolysis of alphaaminobenzylpenicillin. An. Quim Ser. A. 80: 82-84

Patel, D. G., Ritschel, W. A., Chalasani, P., Rao, S. (1991) Biological activity of insulin in microemulsion in mice. J. Pharm Sci. 80: 613-614

Politi, M. I., Chaimovich, H. (1991) Micellar effects on the alkaline hydrolysis of the $N$-alkyl-4-cyanopyridinium ions. An example of micelle-induced regiochemical selectivity. J. Phys. Chem. 4: 207216

Quina, F. H., Chaimovich, H. (1979) Ion exchange in micellar solutions. 1. Conceptual framework for ion exchange in micellar solutions. J. Phys. Chem. 83: 1844-1850
Quina, F. H., Politi, M. J., Cuccovia, I. M., Baumgarten, E., Martins-Franceschetti, S. M., Chaimovich, H. (1980) Ion exchange in micellar solutions. 4. 'Buffered' systems. J. Phys. Chem. 84: 361-365

Quina, F. H., Politi, M. J., Cuccovia, 1. M., Martins-Franchetti, S. M., Chaimovich, H. (1982) Alkaline hydrolysis in micellar sodium dodecyl sulphate. The binding of $\mathrm{OH}$ to anionic micelles. In: Mittal, K., Fendler, E. J. (eds) Solution Chemistry of Surfactants. Theoretical and Applied Aspects. Plenum Press, New York, pp 1125-1136

Razvi, N., Beg, A. E. (1981) Behavior of cationic micelle on the hydrolysis of procaine formulation. J. Chem. Soc. Pak. 3: 121-124

Razvi, N., Beg, A. E. (1982) Interaction of procaine with sodium dodecylsulfate and cetyltrimethylammonium bromide micelles. J. Pharm. (Univ. Karachi) 1: 43-48

Razvi, N., Talib, N., Bhuri, R. A. S., Beg, A. E. (1984) Kinetics of drugs in micellar systems. Pak. J. Pharmacol. 1: 11-20

Rodenas, E., Vera, S. (1985) Iterative calculation method for determining the effect of counterions on acetylsalicylate esters hydrolysis in cationic micelles. J. Phys. Chem. 89: 513-516

Romsted, L. S. (1977) A general kinetic theory of rate enhancements for reactions between organic substrates and hydrophilic ions in micellar systems. In: Mittal, K. L. (ed.) Micellization, Solubilization, and Microemulsions. Plenum Press, New York, pp 509-530

Romsted, L. S. (1984) Micellar effects on reaction rates and equilibria. In: Mittal, K. L., Lindman, B. (eds) Surfactants in Solution. Plenum Press, New York, pp 1015-1069

Schreier, S., Frezzatti, Jr., W. A., Araujo, P. S., Chaimovich, H., Cuccovia, I. M. (1984) Effect of lipidic membranes on the apparent pK of the local anesthetic tetracaine. Spin label and titrations studies. Biochim. Biophys. Acta 769: 231-237

Schreier, S., Amaral, A. T., Stachissini, A. S., Bianconi, M. L. (1986) Electron spin resonance study of benzoic acid esters, analogs of local anaesthetics, interaction with membranes, aggregation and hydrolysis. Bull. Magn. Res. 8: 166-170

Sepulveda, L., Lissi, E., Quina, F. (1986) Interactions of neutral molecules with ionic micelles. Adv. Coll. Int. Sci. 25: 1-57

Shimizu, E., Kambe, Y. (1988) Light scattering of chlorpromazine hydrochloride micelles. Nippon Kagaku Kaishi 5: 719-723

Simonelli, A. P., Aboutaled, A. E., Abdel-Rahaman, A. (1984) Solubilization and stability of clonazepam by different classes of surfactants. Bull. Pharm. Sci. (Assiut Univ.) 7: 363-379

Suleiman, M. S., Nagib, N. M. (1990) Kinetics of alkaline hydrolysis of indomethacin in the presence of surfactants and cosolvents. Drug Dev. Ind. Pharm. 16: 695-706

Tanford, C. (1980) The Hydrophobic Effect. 2nd edn, Wiley-Interscience, New York

Thoma, K., Albert, K. (1983) Colloidal association of tri- and tetracyclic antidepressants and neuroleptics. Pharm. Acta Helv. 58: $279-288$

Thoma, K., Herzfeldt, C. D. (1988a) Colloid association and biological availability of local anesthetics. Part 1 . Surface activity studies on critical micelle concentrations. Pharm. Acta Helv. 63: 34-39

Thoma, K., Herzfeldt, C. D. (1988b) Colloid association and biological availability of local anaesthetics. Part 2. Studies on solvent effects and micelle weight. Pharm. Acta Helv. 63: 40-45

Thoma, K., Kasper, F. R. (1988) Colloid association and biological availability of local anesthetics. Part 8 . Relation between physicochemical properties and mixed-micelles formation. Pharm. Acta Helv. 63: 160-163

Thoma, K., Siemer, E. (1976a) Colloidal association of antihistamines 1. Pharm. Acta Helv. 51: 50-58

Thoma, K., Siemer, E. (1976b) Colloidal association of antihistamines. 2. Pharm. Acta Helv. 51: 59-65

Tsuji, A., Matsuda, M., Miyamoto, E., Yamana, T. (1978) Effects of surfactants on degradation of penicillins and cephalosporins in acidic medium. J. Pharm. Pharmacol. 30: 442-444

Tsuji, A., Nakashima, E., Deguchi, Y., Nishide, K. (1981) Degradation kinetics and mechanism of aminocephalosporins in aqueous solution, cefadroxil. J. Pharm. Sci. 70: 1120-1128

Tsuji, A., Miyamoto, E., Matsuda, M., Nishimura, K., Yamana, T. (1982) Effects of surfactants on the aqueous stability and solubility of beta-lactam antibiotics. J. Pharm. Sci. 71: 1313-1318 
Turro, N. J., Aikawa, M. (1979) Dynamics of molecular oxygen in micellar solutions. Chem. Phys. Lett. 64: 473-478

Vera, S., Rodenas, E. (1984) Basic hydrolysis of acetylsalicylic acid micellar solutions. Influence of micelle counterions. An. Real. Acad. Farm. 50: 73-84

Vera, S., Rodenas, E. (1986a) Influence of $N$-cetyl- $N, N, N$-trimethylammonium bromide counterion in the basic hydrolysis of negatively charged aromatic esters. J. Phys. Chem. 90: 3414-3417

Vera, S., Rodenas, E. (1986b) Inhibition effect of cationic micelles on the basic hydrolysis of aromatic esters. Tetrahedron 42: 143-149

Vera, S., Rodenas, E. (1988a) Alkaline hydrolysis of negatively charged aromatic esters in micellar phase. Ionic Model. An. Quim Ser. A 84: 174-178

Vera, S., Rodenas, E. (1988b) Effect of the temperature in the micellar basic hydrolysis of acetylsalicylic acid. J. Chim. Phys. 85: 451-453

Vera, S., Rodenas, E., Ortega, F., Otero, C. (1983) Inhibition effect of cationic micelles on the hydrolysis of acetylsalicylic acid. J. Chim. Phys. 80: 543-545

Voigth, R., Bornschein, M. (1982) Lehrbuch der Pharmazeutischen Technologie. Acribia, Zaragoza

Yamana, T., Tsuji, A. (1976) Comparative stability of cephalosporins in aqueous solution: kinetics and mechanisms of degradation. J. Pharm. Sci. 65: 1563-1574

Yashuara, M., Sato, F., Kimura, T., Muranishi, S., Sezaki, H. (1977) Catalytic effect of cationic surfactants on degradation of cephalexin in aqueous solution. J. Pharm. Pharmacol. 29: 638-640

Zanette, D., Chaimovich, H. (1992) Effect of hexadecyltrimethylammonium bromide micelles on the rate of oxymolysis of esters. J. Phys. Org. Chem. 5: 341-348

Zarina, M. S. M., Anwar, E. B., Nighat, R. (1986) The effect of changes in the polarity of the reaction solvent (the medium) upon reaction of a cationic micelle with benzocaine. Pharm. Acta Helv. 61: $59-64$ 